\title{
Prosodic Effects on Pronoun Interpretation in Italian
}

\author{
Lydia White, Heather Goad, Jiajia Su, Liz Smeets, Marzieh Mortazavinia, \\ Guilherme D. Garcia, and Natália Brambatti Guzzo
}

\section{Introduction}

The present study investigates whether prosody affects how native speakers and L2 speakers of Italian determine antecedents for null and overt pronouns. Our goal is to explain some of the unexpected findings observed for both native speakers and L2ers in the previous literature (e.g., Belletti, Bennati \& Sorace 2007; Sorace \& Filiaci 2006). We propose that these findings reflect prosodic effects which lead to judgments other than those expected if only the interface between syntax and discourse is implicated.

In Italian and other pro-drop languages, the use of an overt or null subject pronoun is determined by the discourse function of the subject of the sentence (e.g., Carminati 2002). The use of an overt subject signals a change in topic while a null pronoun is typically associated with topic continuation. The notion of $[ \pm$ topic shift $]$ and the choice of a null or overt pronoun correlate with the syntactic position of the antecedent. In particular, preverbal subjects are typically discourse topics. In an intra-sentential context like (1), native speakers generally prefer a null subject when the antecedent of the pronoun in the subordinate clause is the subject of the main clause (here, Lorenzo) and an overt subject when the antecedent is the object (here, Roberto).

(1) Lorenzo $_{\mathrm{i}}$ ha scritto a Roberto quando $_{\mathrm{i}_{\mathrm{i}}} / \mathrm{lui}_{\mathrm{j}}$ si è trasferito a Torino.

'Lorenzo wrote to Roberto when (he) moved to Turin.'

Carminati (2002) expresses the relationship between the syntactic position of the antecedent and pronoun choice as the Position of Antecedent Hypothesis (PAH), a processing constraint whereby null pronouns prefer antecedents in Spec IP whereas overt pronouns prefer their antecedents to be elsewhere in the syntactic structure. ${ }^{1}$

\footnotetext{
* Dept of Linguistics, McGill University, Montreal, Qc, Canada; lydia.white@mcgill.ca, heather.goad@mcgill.ca. We would like to thank Carlotta Lega and Simone Riva for help with recording of the stimuli and Aron Hirsch for discussion. This work was supported by grants from SSHRC and FRQSC.

${ }^{1}$ Note that constituents in Spec IP are not necessarily subjects and that subjects are not always positioned in Spec IP. The PAH is a structurally based processing strategy whereby the syntactic position is relevant, not the grammatical function of the antecedent. In the experiments under discussion, the constituent in Spec IP is always the grammatical subject.
}

(C) 2017 Lydia White, Heather Goad, Jiajia Su, Liz Smeets, Marzieh Mortazavinia, Guilherme D. Garcia, and Natália Brambatti Guzzo. Proceedings of the 41st annual Boston University Conference on Language Development, ed. Maria LaMendola and Jennifer Scott, 744-752. Somerville, MA: Cascadilla Press. 


\section{Previous findings on anaphora resolution}

Previous findings on the interpretation of null and overt pronouns by Italian native speakers (using online and offline tasks) show a significant interaction between type of pronoun and position of antecedent. For example, in a selfpaced reading task, Filiaci, Sorace and Carreiras (2013) showed that with null pronouns in the subordinate clause, sentences with a pragmatic bias towards a subject antecedent interpretation were read significantly faster than those biased towards an object antecedent. In other words, a bias against the expected interpretation of a pronoun induces a processing cost.

Evidence from previous studies shows that L2ers allow subject antecedents for overt pronouns more often than native speakers do, even at near-native levels of proficiency, suggesting some insensitivity to the PAH or the [ \pm topic shift] requirement (Sorace \& Filiaci 2006; Belletti et al. 2007). The authors suggest that these results reflect unsuccessful mastery of the discourse constraints on the use of overt pronouns, possibly due to transfer from the L1, English. According to Sorace and Filiaci (2006), the [+ topic shift] feature is un(der)-specified in L2 learners' grammars because this feature is not operative in the L1. The overt pronoun is thus not interpreted as necessarily involving a shifted topic. Only overt pronouns are affected, according to these authors, since properties of pro are determined by the null subject parameter, which has been successfully reset to the Italian value.

However, in both of these studies there are some discrepancies in the results that remain unexplained. In Sorace and Filiaci's (2006) study, native speakers and L2ers allow a null pronoun to take a non-subject antecedent about $50 \%$ of the time. Similarly, in Belletti et al. (2007), participants allow null subject pronouns to take object antecedents as often as subject antecedents, with no significant different between the native speakers and the L2ers. In the present study, we suggest that prosodic factors may be responsible for these unexpected results. In view of this, we turn now to potential prosodic effects on pronoun interpretation.

\section{Potential prosodic effects on pronoun interpretation}

Carminati (2002) observes differences in subject antecedent choices depending on the type of subordinate clause present in a sentence, which can bias the participant to a subject or object interpretation. Specifically, the syntax of conditional clauses is argued to be different from temporal clauses; prosodic grounds are used to motivate the distinction.

In comparing conditional clauses starting with if and temporal clauses starting with when, Carminati finds more subject antecedent choices for null 
pronouns in subordinate clauses of the former type than the latter type (89\% vs. $76 \%$ ). Because an intonational break is more naturally inserted in front of an ifclause, she suggests that these clauses are attached higher than temporal clauses. In other words, the two types of subordinate clause are attached to different syntactic positions, either adjoined high (to IP) or low (to VP). This difference is shown in (2) (adapted from Carminatti 2002).

(2)

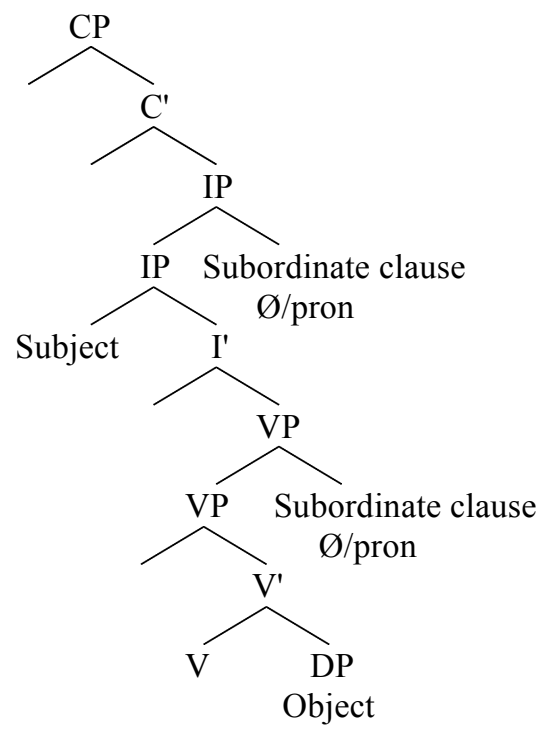

The presence or absence of an intonational break and its consequences for high or low attachment of the subordinate clause will become important when we present our hypotheses about prosodic effects on pronoun interpretation in section 4. Following the Late Closure principle of Frazier (1978), we assume that incoming clauses are generally attached to the clause currently being processed. This means that subordinate clauses should normally prefer to attach low. However, if a pause interrupts the main and subordinate clauses, we interpret this to mean that the subordinate clause is attached higher in the tree, as shown in (2), such that it is parsed as being further away from the subject in Spec IP and, hence, not subject to the PAH.

Another relevant factor concerns the presence or absence of contrastive stress on the overt pronoun. Italian allows overt pronouns to be stressed for emphatic reasons. Sorace and Filiaci (2006) mention that the PAH does not apply to stressed pronouns and that stressed pronouns can take subjects as their antecedents. Importantly, however, the effects of stress on anaphora resolution have not been explicitly studied or controlled for in previous studies. 


\section{Hypotheses}

In this paper, we experimentally test the possibility that there are prosodic effects on the interpretation of null and overt pronouns in pro-drop languages, which lead to judgments other than those expected if only the PAH or the interface between syntax and discourse is implicated (i.e., considerations of topichood). We propose that the two prosodic factors identified in section 3 can affect the choice of antecedent for a pronoun, namely the presence of a pause between the main and subordinate clauses and the presence of stress on an overt pronoun. In earlier literature, it is impossible to discern the prosodic phrasing assumed by participants because these studies used tasks, such as Picture Verification Tasks, with orthographically-presented stimuli that participants were asked to read to themselves.

It has been well-documented that prosodic cues are used to disambiguate potentially ambiguous sentences across a variety of constructions, for example high versus low attachment of relative clauses by native speakers (e.g., Fodor 2002; Jun 2003; Maynell 1999, 2000) and L2ers (Dekydtspotter et al. 2008; White et al. 2012). Although one may question whether prosody could be involved in the disambiguation of sentences that are not orally produced, precisely this position has been proposed by Fodor (2002) who argues that 'silent prosody' affects interpretation.

Here, we consider whether overt prosody has effects on pronoun interpretation, examining whether the same profile of results is found when prosodic effects are overtly signalled in orally presented stimuli. If so, it is plausible to assume that silent prosody might underlie the results from earlier tasks involving reading. With this goal in mind, we formulate the two hypotheses presented in (3):

(3) a. Hypothesis 1: Effects of pause

A pause between the clauses containing the pronoun and its antecedent will permit an analysis whereby the subordinate clause is too high in the structure for a strategy like the PAH to operate. As a result, null pronouns will not be restricted to antecedents in Spec IP.

b. Hypothesis 2: Effects of contrastive stress on overt pronouns

When a pronoun is unstressed, the preference will be for an antecedent which is not in Spec IP, typically the object, in accordance with the $\mathrm{PAH}$. When the pronoun bears contrastive stress, this signals a contrast with the object, and will thus favour either the subject or an external referent as antecedent.

\section{Methods}

To test our hypotheses, a judgement task was designed where participants were auditorily presented with biclausal sentences ( $\mathrm{n}=70+10$ fillers). Our study 
focuses on a particular subset of these stimuli $(\mathrm{n}=30)$, involving mainsubordinate clause order and forwards anaphora; see (4). The three factors manipulated were pronoun (null/overt), pause (pause/no pause, indicated by '\#' in (4)), and stress (contrastive/unstressed). Each sentence was followed by one of three comments containing a possible referent for the pronoun in the target sentence: subject, object, or external, as shown in (4). The test sentences were recorded by a female native speaker of Italian; the comments were recorded by a male native speaker.

(4) Target sentence:

'Lorenzo ha scritto a Roberto (\#) quando Ø/lui si è trasferito a Torino.'

'Lorenzo wrote to Roberto (\#) when (he) moved to Turin.'

a) Comment (subject):

'È Lorenzo che si è trasferito a Torino.'

'It is Lorenzo who moved to Turin.'

b) Comment (object):

'È Roberto che si è trasferito a Torino.'

'It is Roberto who moved to Turin.'

c) Comment (external):

'È una persona diversa da Lorenzo e Roberto che si è trasferito a Torino.'

'It is a person other than Lorenzo or Roberto who moved to Turin.'

All target sentences were preceded by a pause $(500 \mathrm{~ms})$, a beep $(700 \mathrm{~ms})$ and another pause $(1000 \mathrm{~ms})$. A pause of $1000 \mathrm{~ms}$ was also added between the end of each target sentence and the beginning of each comment. Finally, in conditions where a pause was present ('\#' in (4)), the duration of said pause was $400 \mathrm{~ms}$.

Once participants heard a target sentence followed by a comment, they were asked to indicate whether they agreed with the comment on a 6-point scale $(1=$ completely agree; $6=$ completely disagree). There was also a 'don't know' option.

To avoid sequences of identical comment types, stimuli were presented in a pseudo-randomized fashion. In addition, comments were balanced across the three versions of the experiment ( $4 a-4 c$ above), as well as the three different conditions mentioned above (pronoun, pause and stress).

The participants were high intermediate to advanced learners of Italian $(n=$ 8). Their L1 was either Dutch or English, neither of which is a pro-drop language. The control group consisted of 10 native speakers of Italian.

\section{Predictions}

The specific predictions that stem from our hypotheses in section 4 are as follows. In the null pronoun condition where no pause interrupts the clauses, the 
preferred antecedent will be the subject, as expected under previous approaches. However, when a pause interrupts the clauses, we expect an increase in object or external referent judgments, consistent with Hypothesis 1.

In the overt pronoun conditions where the pronoun is unstressed, the preferred antecedent will be the object, as expected under previous approaches. This prediction holds regardless of whether or not a pause interrupts the clauses.

When the pronoun is contrastively stressed, however, there should be fewer acceptances of object antecedents, because contrastive stress signals a contrast with the normally preferred antecedent object. This should lead to an increase in choice of subject or external referents, consistent with Hypothesis 2.

Finally, when the pronoun is contrastively stressed and a pause interrupts the clauses, we expect an increase in acceptances of external referents as antecedents. As mentioned, contrastive stress signals a contrast with the object, consistent with Hypothesis 2, but the subject is 'too far away', consistent with Hypothesis 1.

The predictions for each condition are summarized in Table 1.

\begin{tabular}{|l|l|l|}
\hline Pronoun condition & No Pause & Pause \\
\hline Null & Subject & $\begin{array}{l}\text { Increase in object or } \\
\text { external }\end{array}$ \\
\hline Overt unstressed & Object & Object \\
\hline Overt contrastive & $\begin{array}{l}\text { Increase in subject } \\
\text { or external }\end{array}$ & Increase in external \\
\hline
\end{tabular}

Table 1. Predictions by condition.

\section{Results}

Figure 1 shows the overall results for null versus overt pronouns. In all figures, the black portions in the bars indicate the rate of agreement with each comment; the white portions, the rate of disagreement.
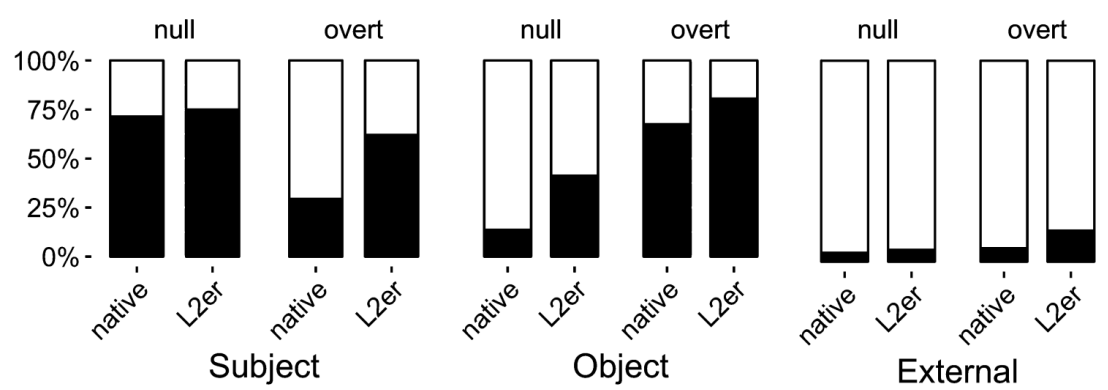

Figure 1. Subject/Object/External responses by pronoun. 
As is evident from Figure 1, the overall results are consistent with earlier studies investigating the syntax-discourse interface: for both native speakers and L2ers, subjects are strongly preferred as antecedents for null pronouns (first pair of panels in Fig. 1) while objects are strongly preferred for overt pronouns (second pair of panels). Although the L2ers perform like native speakers in these two respects, the figure also shows that they overaccept subject responses for overt pronouns and object responses for null pronouns; we will return to both of these findings below.

Interestingly, the preferences observed in Figure 1 in terms of subject responses for null pronouns and object responses for overt pronouns are more definitive than what has been reported in earlier studies, suggesting that oral presentation of stimuli may be more favourable for eliciting judgments in situations involving potentially ambiguous sentences.

Turning to Figure 2, as predicted, both groups show increased agreement with object comments for null pronouns when the clauses are separated by a pause (compare the middle panels in Fig. 2). This likely contributes to the L2ers' high rate of acceptance of object responses for null pronouns observed in Figure 1. These results are consistent with Hypothesis 1 , which states that introduction of a pause before the subordinate clause permits an analysis whereby this clause occurs higher in the structure. Consequently, Spec IP is less accessible and coreference with the subject is no longer the only option. ${ }^{2}$
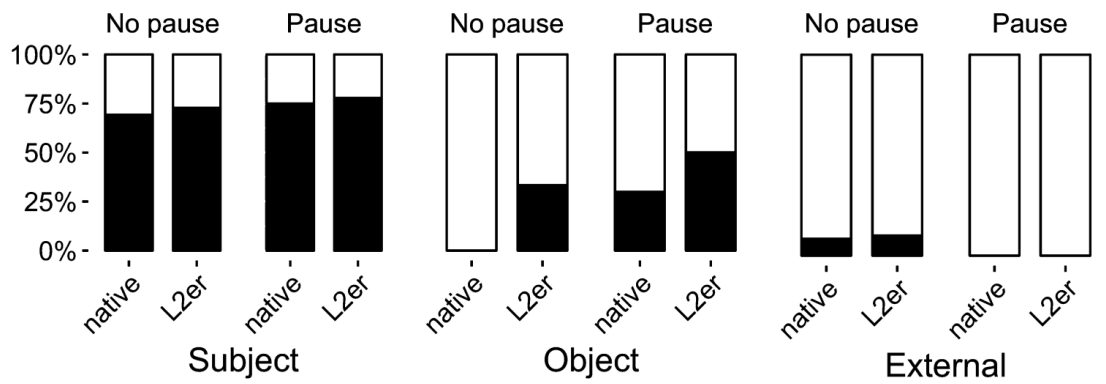

Figure 2. Subject/Object/External responses for null pronouns by pause.

Turning finally to Figure 3, the upper panels provide participants' responses to overt pronouns that are unstressed. The first pair of panels shows a decrease in L2ers' acceptance of subject responses when there is a pause, which may account for their overuse of overt pronouns with subjects in Figure 2.

\footnotetext{
${ }^{2}$ The subordinate clauses in our stimuli were of two types: conditional clauses (introduced by if) and temporal clauses (introduced by when, after). Although the number of stimuli for each type is low, we did not find a difference between them, suggesting that high and low attachment is not tied to the type of clause (contra Carminati 2002), but is instead tied to the presence or absence of pause.
} 
The lower panels provide participants' responses to overt pronouns that are contrastively stressed. In comparing the upper and lower panels, it can be seen that contrastively stressing a pronoun has a considerable effect on participants' responses. As predicted, it reduces their acceptance of object responses, for the native speakers in the no pause condition, and for the L2ers in both the no pause and pause conditions. Contrastive stress in the pause condition also leads to an increase in L2ers' acceptance of external referents, as predicted, although the lack of an increase for the native speakers remains unexplained. Both of these findings are consistent with Hypothesis 2, which states that when the pronoun bears contrastive stress, this signals a contrast with the normally preferred object antecedent, thus favouring either the subject or an external referent as antecedent.

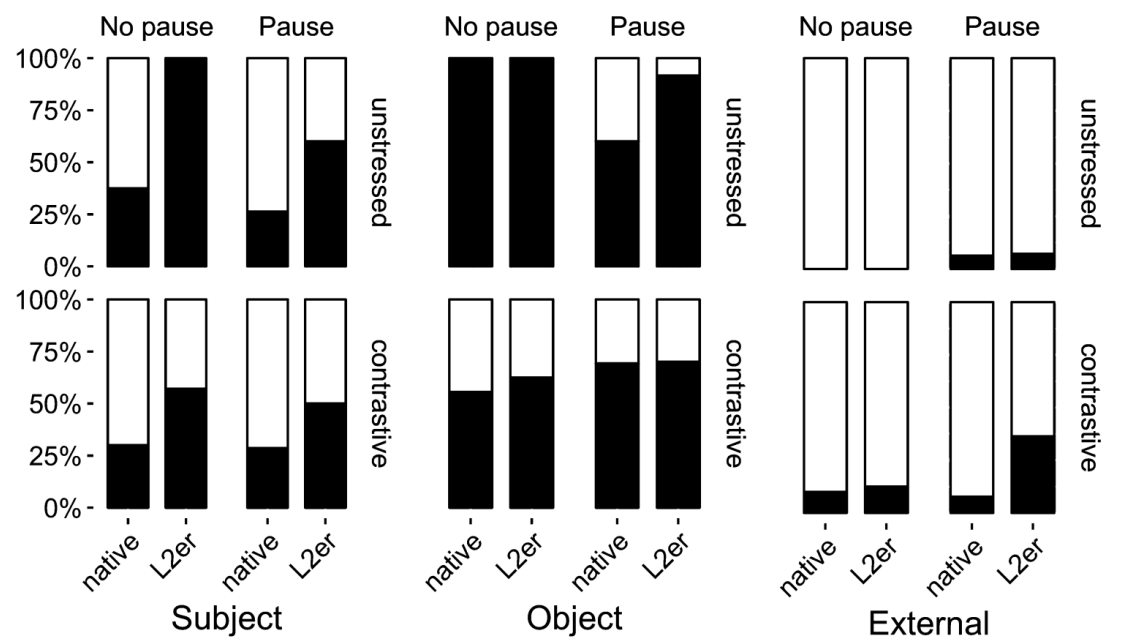

Figure 3. Subject/Object/External responses for overt pronouns by pause and stress.

\section{Conclusion}

In conclusion, we have demonstrated that prosodic factors affect the ways in which pronouns are interpreted by native speakers and L2ers with respect to participants in the discourse. We hypothesized that two aspects of earlier results might be amenable to a prosodic account. Firstly, several studies report that native speakers and L2ers do not restrict null pronouns to taking subject antecedents, allowing them to have object antecedents much of the time. We proposed that this might be due to the presence of a pause, inserted by participants in silent reading. Our results suggest that this explanation is on the right track: when a pause is overtly present in our stimuli, the choice of object antecedents by both groups increases, as shown in Figure 2. The second issue 
that we looked at was contrastive stress. Presence of stress reduced the incidence of object responses, particularly for the L2ers, and resulted in a corresponding increase in responses favouring an external referent. These results suggest, indirectly, that the previously reported overacceptance of subject antecedents for overt pronouns by L2ers might also relate to stress imposed in silent reading, which, however, led to an increase in the selection of subject rather than external referents. In closing, it must be borne in mind that our results can only be taken as suggestive at this point, given the relatively small number of subjects and stimuli. They nevertheless provide a point of departure for future research into the role of prosody in pronoun interpretation.

\section{References}

Belletti, Adriana, Elisa Bennati \& Antonella Sorace. 2007. Theoretical and developmental issues in the syntax of subjects: Evidence from near-native Italian. NLLT 25: 657-689.

Carminati, Maria Nella. 2002. The processing of Italian subject pronouns. PhD dissertation, University of Massachusetts Amherst.

Dekydtspotter, Laurent, Bryan Donaldson, Amanda C. Edmonds, Audrey Liljestrand Fultz \& Rebecca A. Petrush. 2008. Syntactic and prosodic computations in the resolution of relative clause attachment ambiguity by English-French learners. Studies in Second Language Acquisition 30: 453-480.

Filiaci, Francesca, Antonella Sorace \& Manuel Carreiras. 2013. Anaphoric biases of null and overt subjects in Italian and Spanish: A cross-linguistic comparison. Language and Cognitive Processes. DOI:10.1080/01690965.2013.801502.

Fodor, Janet D. 2002. Prosodic disambiguation in silent reading. In Masako Hirotani (ed.), Proceedings of NELS 32 (pp. 113-132). University of Massachusetts, Amherst: GLSA.

Frazier, Lyn. 1978. On comprehending sentences: Syntactic parsing strategies. PhD dissertation, University of Connecticut, Storrs.

Jun, Sun-Ah. 2003. Prosodic phrasing and attachment preferences. Journal of Psycholinguistic Research 32: 219-249.

Maynell, Laurie. 1999. Effect of pitch accent placement on resolving relative clause ambiguity in English. Poster presented at the 12th Annual CUNY Conference on Human Sentence Processing, New York, NY.

Maynell, Laurie. 2000. Prosodic effects on relative clause attachment. Poster presented at the 13th Annual CUNY Conference on Human Sentence Processing, La Jolla, CA.

Sorace, Antonella \& Francesca Filiaci. 2006. Anaphora resolution in near-native speakers of Italian. SLR 22: 339-368.

White, Lydia, Heather Goad, Daniel Goodhue, Hyekyung Hwang \& Moti Lieberman. 2012. Syntactic ambiguity resolution in L2 parsing: Effects of prosodic boundaries and constituent length. BUCLD 37 Proceedings Supplement. http://www.bu.edu/bucld/supplementvol37/. 


\section{Proceedings of the 41st annual Boston University Conference on Language Development}

\section{edited by Maria LaMendola and Jennifer Scott}

Cascadilla Press Somerville, MA 2017

\section{Copyright information}

Proceedings of the 41st annual Boston University Conference on Language Development

(C) 2017 Cascadilla Press. All rights reserved

Copyright notices are located at the bottom of the first page of each paper.

Reprints for course packs can be authorized by Cascadilla Press.

ISSN 1080-692X

ISBN 978-1-57473-076-0 (2 volume set, paperback)

ISBN 978-1-57473-176-7 (2 volume set, library binding)

\section{Ordering information}

To order a copy of the proceedings or to place a standing order, contact:

Cascadilla Press, P.O. Box 440355, Somerville, MA 02144, USA

phone: 1-617-776-2370, sales@ cascadilla.com, www.cascadilla.com 